\title{
Parasitism by tachinid parasitoids (Diptera: Tachinidae) in connection with their survival strategy
}

\author{
Eiko KAN, ${ }^{1, *, \dagger}$ Narao FUKUHARA $^{2}$ and Toshitaka HIDAKA ${ }^{3, \neq}$ \\ ${ }^{1}$ Japan Science and Technology Corporation/Forestry and Forest Products Research Institute (FFPRI); Ibaraki 305-8687, Japan \\ ${ }^{2}$ National Institute of Agro-Environmental Science; Tsukuba, Ibaraki 305-8604, Japan \\ ${ }^{3}$ The University of Shiga Prefecture; Hikone, Shiga 522-8533, Japan
}

(Received 19 August 2002; Accepted 6 December 2002)

\begin{abstract}
Parasitism by tachinid parasitoid(s) was investigated for 7 species of lepidopteran host larvae collected in Ibaraki Prefecture, Japan in 1997 and 1998. A total of 188 tachinid larvae emerged from 157 out of 1,051 field-collected hosts. Compsilura concinnata (Meigen), Exorista japonica (Townsend), Pales pavida (Meigen), Senometopia excisa (Fallén), Zenillia libatrix (Panzer), Blepharipa sp. and Exorista spp. were identified. New hosts of E. japonica, P. pavida and Z. libatrix were recorded. Emergence of more than 1 conspecific larva from a single host individual was observed in hosts parasitized by E. japonica, P. pavida, S. excisa or Blepharipa sp. Three different types of species combinations in multiparasitism were also observed: (1) E. japonica and P. pavida; (2) E. japonica and Tachinidae sp.; and (3) Blepharipa sp. and Tachinidae spp. These results suggest that E. japonica, P. pavida, S. excisa and Blepharipa sp. larvae potentially have a high "tolerance" for the presence of other tachinid larvae. Probably, this enables these tachinid larvae to coexist tolerantly with conspecific and/or heterospecific tachinid larvae and, therefore, benefits their survival when there are not sufficient hosts available.
\end{abstract}

Key words: Tachinidae; parasitism; lepidopteran hosts; multiparasitism

\section{INTRODUCTION}

Parasitoids are well-known natural enemies of insect pests. They complete their larval development only in a single host body, feeding and killing the parasitized host. The host body is the only food resource for parasitoid larvae. Parasitoid adults are continuously faced with changing conditions in their search for and encounter with hosts. Factors such as host availability and quality affect the fitness of an ovipositing female parasitoid. So far most studies on parasitoids have focused on hymenopteran parasitoids and little is known about parasitism by dipteran parasitoids.

Tachinid parasitoids parasitize various insects, such as Lepidoptera, Orthoptera and Coleoptera. Female flies of some tachinid species attack only adults of Orthoptera or Coleoptera (Clausen and King, 1927; Cade, 1975; Robert et al., 1992; Walker, 1993; Allen, 1995; Lehmann and Heller, 1998), while the female flies of many other tachinid species attack mainly larvae of Lepidoptera. In the former case, the host quality and quantity is considerably stable, but in the latter case it changes drastically in a relatively brief period during the host's developmental stages. Although little is known about reproductive strategies of tachinid females, they have been studied experimentally by several authors (e.g. Stapel et al., 1997). Stapel et al. (1997) investigated female adjustment of progeny number in response to different host conditions. They demonstrated experimentally that the maximum number of emerging tachinid larvae (Lespesia archippivora) per host (Spodoptera exigua) increased with the host instar at the time of parasitization.

As mentioned above, the tachinid parasitoids complete their larval development only in a single host body. In several lepidopteran host species, a single host individual is often attacked by different tachinid species and their larvae occur together in a single host, e.g., larvae of 2 tachinid species (Compsilura concinnata and Epicampocera succincta) occurring together in the body of the hosts

\footnotetext{
${ }^{*}$ To whom correspondence should be addressed at: E-mail: eikokan@ta.laox.net

${ }^{\dagger}$ Present address: Department of Medical Zoology, School of Medicine, Mie University; Tsu, Mie 514-0001, Japan

${ }^{\ddagger}$ Present address: Research Institute for Humanity and Nature; Kyoto 602-0878, Japan
} 
(Pieris larvae) (Iwao and Ohsaki, 1993, 1996). Furthermore, conspecific larvae of $C$. concinnata and E. succincta also often occur together in a host body (Iwao and Ohsaki, 1993, 1996). Some survival strategies of tachinid larvae are expected in these 2 cases because every tachinid larva requires a sufficient food resource for completing its larval development. Iwao and Ohsaki $(1993,1996)$ investigated inter- and intraspecific interactions among larvae of $C$. concinnata and E. succincta parasitizing Pieris larvae in the field. C. concinnata, an extreme generalist, exhibited scramble-type competition, sharing the host with other conspecifics and suffering reduced body size as a result. On the other hand, E. succincta, a specialist on Pieris larvae, showed contest-type intraspecific competition, eliminating all other conspecific larvae. C. concinnata had a much higher chance of survival when these 2 tachinid species occurred together in a single host individual (Iwao and Ohsaki, 1993, 1996).

In this study parasitism by tachinid parasitoids was investigated in detail for field-collected lepidopteran host larvae to determine parasitic status of the tachinid parasitoids in the field. Results are discussed in connection with the survival strategy of tachinid larvae.

\section{MATERIALS AND METHODS}

Hosts. Larvae of a total of 7 species of Lepidoptera were collected from their host plants in 3 different sites in Ibaraki Prefecture, Japan in 1997 and 1998. In each collection of 1 host species in a day, the host larvae were collected by 1 person randomly from branches of the trees up to about $2 \mathrm{~m}$ above the ground and the duration of each sampling was $30 \mathrm{~min}$. For each host species, the larval instar of each collected host was determined by its head capsule width based on data on growth of head capsule (Kan, unpublished data).

In the 1997 collection, larvae of 3 species of Lepidoptera were captured: (1) Hyphantria cunea (Drury) larvae from 3 walnut trees, Juglans mandshurica Maxim. var. sachalinensis (Miyabe et Kudo) Kitamura (Family: Juglandaceae) at Kannondai in Tsukuba City on 26 August; (2) H. cunea larvae from 2 willow trees, Salix petsusu Kimura (Family: Salicaceae) at Forestry and Forest Products Research Institute (FFPRI) in Kukizaki Town in Inashiki District on 1 September; (3) Phalera flavescens (Bremer et Grey) larvae from 2 cherry trees, Prunus pendula Maxim. f. pendula (Family: Rosaceae) at FFPRI on 10 September; and (4) 1 larva of Graphium sarpedon Linnaeus from a camphor tree, Cinnamomum camphora (L.) Presl (Family: Lauraceae) at Kannondai on 1 October.

In the 1998 collection, larvae of 4 species of Lepidoptera were captured: (1) 2 different sample groups of Pryeria sinica Moore larvae were obtained from 2 different populations of spindle trees, Euonymus japonicus Thunb. (Family: Celastraceae) at 2 different sites in FFPRI. One group from 15 spindle trees of one population on 16 April and the other group from another 20 spindle trees of the other population on 30 April; (2) 2 groups of $\mathrm{Pi}$ dorus glaucopis (Drury) larvae were obtained from 2 different populations of eurya trees, Eurya japonica Thunb. (Family: Theaceae) at 2 different sites in Kannondai. One group from 10 eurya trees of one population on 12 May and the other group from another 15 eurya trees of the other population on 21 May; (3) 2 groups of Chalcosia remota (Walker) larvae were obtained from sweetleaf trees, Symplocos chinensis (Lour.) Druce var. leucocarpa (Nakai) Ohwi f. pilosa (Nakai) Ohwi (Family: Symplocaceae). One group from a sweetleaf tree at Otto in Tsuchiura City on 15 May and the other group from 2 sweetleaf trees at FFPRI on 18 May; and (4) Dictyoploca japonica (Moore) larvae from a walnut tree, Pterocarya rhoifolia Sieb. et Zucc. (Family: Juglandaceae) at Kannondai on 4 June.

These field-collected host larvae were kept individually in our FFPRI laboratory under conditions of $25 \pm 1{ }^{\circ} \mathrm{C}$ and $16 \mathrm{~L}: 8 \mathrm{D}$ until the host larvae died with or without yielding tachinid larvae, or until the hosts successfully developed into adults. The host larvae were fed fresh leaves of their food plants which did not bear any tachinid eggs.

Tachinid parasitoids. The number of tachinid larvae emerging from each host was recorded. The tachinid larvae emerged from their hosts after the hosts died. Pupariation of the tachinid larvae was observed within about $12 \mathrm{~h}$ after emergence under laboratory conditions. The puparia were kept individually and allowed to eclose in a plastic container $(2.5 \times 3.5 \times 2.5 \mathrm{~cm})$ under the same conditions as mentioned above, with a piece of filter paper $(1.5 \times$ $1.5 \mathrm{~cm}$ ) well moistened with distilled water to maintain a high moisture level. The adult flies obtained were identified and recorded. 


\section{RESULTS AND DISCUSSION}

\section{Records of hosts, mortality and adult emergence}

Records of the hosts, their mortality and the number of their adult emergences are shown in Table 1. A total of 1,051 host larvae consisting of 7 species from 5 families were collected in 1997 and 1998 (403 and 648, respectively). All larvae were at the last instar, except for $P$. sinica collected on 16 April 1998 which were third instar larvae. As shown in Table 1, 157 out of the 1,051 host larvae were parasitized. Parasitoids emerging from the 157 parasitized hosts were only tachinids. In the 196 host bodies which died without yielding parasitoids, no tachinid larvae were found by microscopical observations. Probably, these 196 hosts were killed by other factors, such as improper development, unsuccessful pupation and accidental injury caused by handling.

\section{List of hosts and tachinid parasitoids}

A list of the field-collected hosts and the tachinid parasitoids emerging from them is shown in Table $2 \mathrm{a}$ and $\mathrm{b}$. Tachinid larvae emerged from the hosts at their last larval, prepupal or pupal stage. A total of 188 tachinid larvae emerged from the 157 parasitized hosts. One hundred and twenty-five out of the 188 tachinid larvae successfully developed into adults, making it possible to identify them. They were Compsilura concinnata (Meigen), Exorista japonica (Townsend), Pales pavida (Meigen), Senometopia excisa (Fallén), Zenillia libatrix (Panzer), Blepharipa sp. and Exorista spp. Ten tachinid larvae which emerged from $P$. glaucopis collected on 21 May 1998 (Table 2b) died of unsuccessful adult eclosion and could not be identified. Therefore, they were recorded as Tachinidae spp. This also applied to 2 cases in which the tachinids died at the puparial stage: (1) 12 tachinid larvae which emerged from $P$. flavescens (Table 2a) and (2) 15 tachinid larvae which emerged from $C$. remota collected on 15 May 1998 (Table 2b). The remaining 26 of the 188 tachinid larvae successfully developed into adults but could not be identified even at the generic level, so they were recorded as Tachinidae spp., too.

\section{Percentage parasitism}

As mentioned above, 5 tachinid species $(C$. concinnata, E. japonica, P. pavida, S. excisa and $Z$. libatrix) were identified at the species level. Ninety $(57.3 \%)$ out of the 157 parasitized hosts, which consisted of 6 lepidopteran species, were attacked by these 5 tachinid species and each host was parasitized by a single tachinid species. Percentage parasitism of these 6 host species by the 5 tachinid species is shown in Table 3.

\section{Number of tachinid parasitoids emerging from a single host individual}

The number of tachinid larvae emerging from a single host individual is shown in Table 4. This number was only 1 in $140(89.2 \%)$ out of the 157 parasitized hosts, and it was more than 1 in 17 (10.8\%) out of the 157 hosts. When a host was parasitized by any one of tachinid species $(C$. concinnata, E. japonica, P. pavida, S. excisa and Z. libatrix) the number of tachinid parasitoids emerging from a single host individual is shown in Table 5 . As shown in Table 4, as many as 14 tachinid larvae emerged from a single host individual, $G$. sarpedon, and all of them successfully developed into adults.

The number of tachinid larvae emerging from a single host individual has been reported for some tachinid species parasitizing field-collected lepidopteran hosts. In E. japonica parasitizing Mamestra brassicae (Family: Noctuidae), this number was 1 to 6 (Oku and Kobayashi, 1974). Although the number of $C$. concinnata larvae emerging from a single host individual was only 1 in this study (Table 5), Iwao and Ohsaki (1996) observed that this number was 1 to 3 in C. concinnata parasitizing Pieris larvae (Family: Pieridae). The average number of Thelairia bryanti larvae emerging per host (Platyprepia virginalis, Family: Arctiidae) was about 2 and the muximum was 6 (English-Loeb et al., 1990).

\section{Number of tachinid species emerging from a single host individual}

The number of tachinid species emerging from a single host individual was investigated for each host species (Table 6). This number was only 1 in $152(96.8 \%)$ out of the 157 parasitized hosts. The number was 2 in $4(2.5 \%)$ out of the 157 hosts and this was observed in 3 different cases as follows: (1) 2 larvae (E. japonica and P. pavida) emerging from a single host individual were observed in 1 host, H. cunea; (2) 2 larvae (E. japonica and 


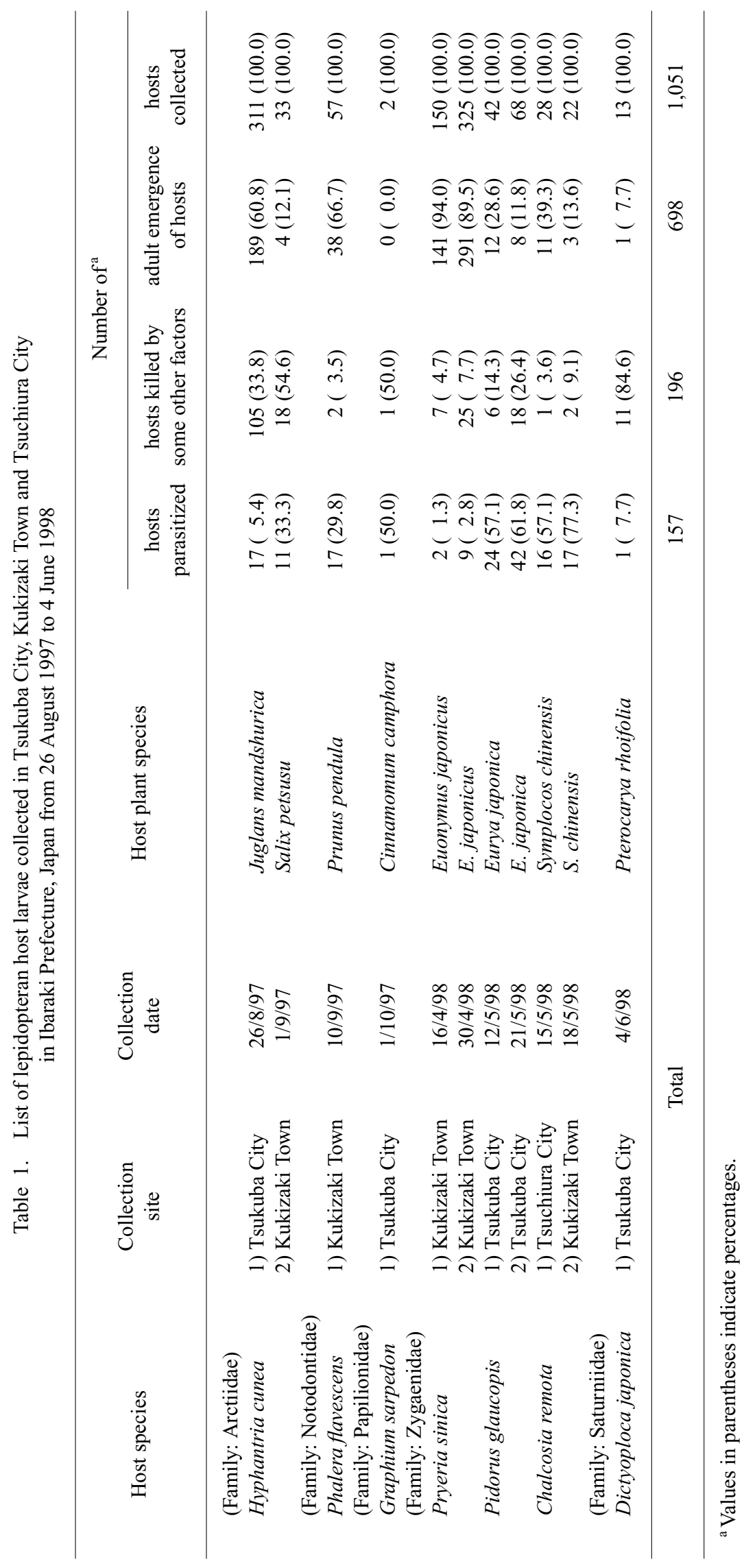


Parasitism by Tachinid Parasitoids

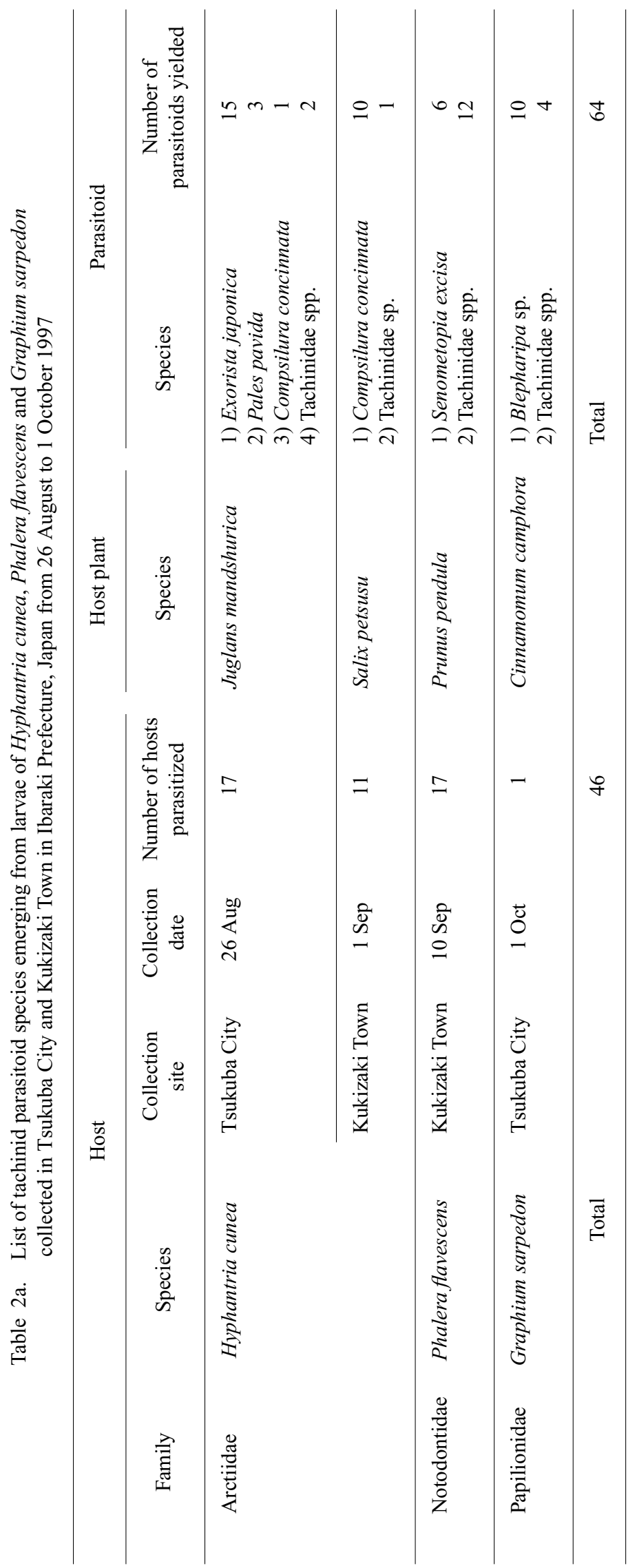




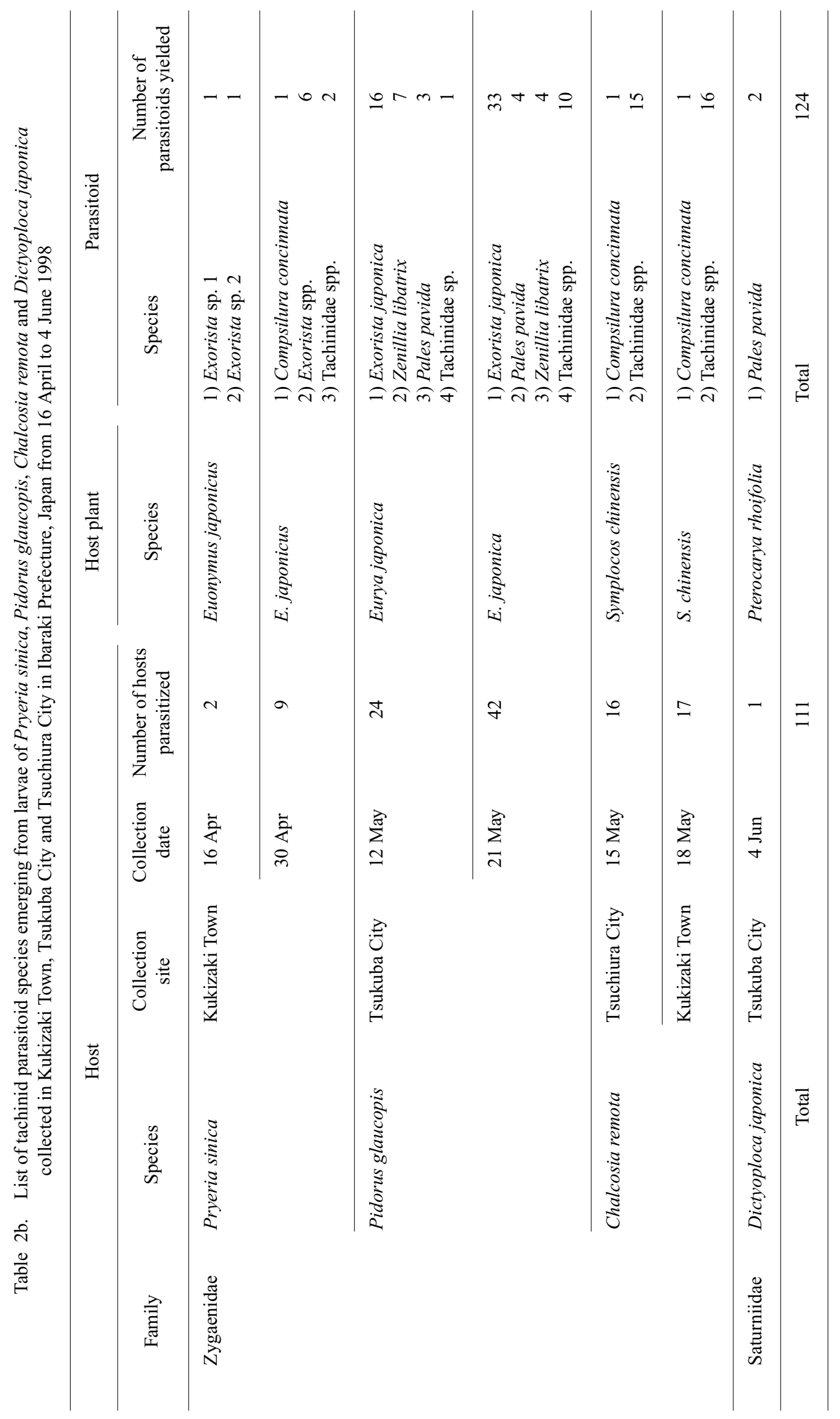


Table 3. Percentage parasitism of 6 lepidopteran host species parasitized by Compsilura concinnata, Exorista japonica, Pales pavida, Senometopia excisa or Zenillia libatrix. For details of hosts, see Table 1.

\begin{tabular}{|c|c|c|c|c|c|c|c|}
\hline \multicolumn{3}{|c|}{ Host } & \multicolumn{5}{|c|}{ Number of hosts parasitized by tachinid species ${ }^{\mathrm{a}}$} \\
\hline Species & $\begin{array}{l}\text { Collection } \\
\text { date }\end{array}$ & $\begin{array}{c}\text { Number of larvae } \\
\text { collected }\end{array}$ & C. concinnata & E. japonica & P. pavida & S. excisa & Z. libatrix \\
\hline \multirow[t]{2}{*}{ Hyphantria cunea } & $26 / 8 / 97$ & 311 & $1(0.3)$ & $11(3.5)$ & $2(0.6)$ & - & - \\
\hline & $1 / 9 / 97$ & 33 & $10(30.3)$ & - & - & - & - \\
\hline Phalera flavescens & $10 / 9 / 97$ & 57 & - & - & - & $5(8.8)$ & - \\
\hline Pryeria sinica & $30 / 4 / 98$ & 325 & $1(0.3)$ & - & - & - & - \\
\hline \multirow[t]{2}{*}{ Pidorus glaucopis } & $12 / 5 / 98$ & 42 & - & $14(33.3)$ & $2(4.8)$ & - & $7(16.7)$ \\
\hline & $21 / 5 / 98$ & 68 & - & $26(38.2)$ & $4(5.9)$ & - & $4(5.9)$ \\
\hline \multirow[t]{2}{*}{ Chalcosia remota } & $15 / 5 / 98$ & 28 & $1(3.6)$ & - & - & - & - \\
\hline & $18 / 5 / 98$ & 22 & $1(4.5)$ & - & - & - & - \\
\hline Dictyoploca japonica & $4 / 6 / 98$ & 13 & - & - & $1(7.7)$ & - & - \\
\hline
\end{tabular}

${ }^{\text {a }}$ Values in parentheses indicate percentage parasitism.

Table 4. Number of tachinid parasitoids emerging from each of 157 tachinid-parasitized lepidopteran hosts. For details of hosts, see Table 1.

\begin{tabular}{|c|c|c|c|c|c|c|}
\hline \multicolumn{2}{|l|}{ Host } & \multicolumn{5}{|c|}{ Number of parasitized hosts } \\
\hline \multirow{2}{*}{ Species } & \multirow{2}{*}{$\begin{array}{l}\text { Collection } \\
\text { date }\end{array}$} & \multicolumn{4}{|c|}{ Number of parasitoids emerging from a single host } & \multirow{2}{*}{ Total } \\
\hline & & 1 & 2 & 3 & 14 & \\
\hline \multirow[t]{2}{*}{ Hyphantria cunea } & $26 / 8 / 97$ & 13 & 4 & 0 & 0 & 17 \\
\hline & $1 / 9 / 97$ & 11 & 0 & 0 & 0 & 11 \\
\hline Phalera flavescens & $10 / 9 / 97$ & 16 & 1 & 0 & 0 & 17 \\
\hline Graphium sarpedon & $1 / 10 / 97$ & 0 & 0 & 0 & 1 & 1 \\
\hline \multirow[t]{2}{*}{ Pryeria sinica } & $16 / 4 / 98$ & 2 & 0 & 0 & 0 & 2 \\
\hline & $30 / 4 / 98$ & 9 & 0 & 0 & 0 & 9 \\
\hline \multirow[t]{2}{*}{ Pidorus glaucopis } & $12 / 5 / 98$ & 21 & 3 & 0 & 0 & 24 \\
\hline & $21 / 5 / 98$ & 35 & 5 & 2 & 0 & 42 \\
\hline \multirow[t]{2}{*}{ Chalcosia remota } & $15 / 5 / 98$ & 16 & 0 & 0 & 0 & 16 \\
\hline & $18 / 5 / 98$ & 17 & 0 & 0 & 0 & 17 \\
\hline Dictyoploca japonica & $4 / 6 / 98$ & 0 & 1 & 0 & 0 & 1 \\
\hline Total & & 140 & 14 & 2 & 1 & 157 \\
\hline
\end{tabular}

Tachinidae sp.) emerging from a single host individual were observed in 1 host, $P$. glaucopis; and (3) 2 larvae (2 Tachinidae spp.) emerging from a single host individual were observed in 2 hosts $(P$. glaucopis). While, as mentioned above, a total of 14 tachinid larvae emerged together from a single host individual ( $G$. sarpedon). They consisted of 10 larvae of Blepharipa sp. and 4 larvae of Tachinidae spp. These 4 larvae of Tachinidae spp. consisted of 2 to 4 tachinid species. Therefore, in $G$. sarpedon, the number of tachinid species emerging from a single host individual was recorded as 3 to
5. These results show multiparasitism by different tachinid species, i.e., (1) E. japonica and P. pavida, (2) E. japonica and Tachinidae sp., (3) Tachinidae spp. and (4) Blepharipa sp. and Tachinidae spp.

\section{GENERAL DISCUSSION}

In the present study, the 5 tachinid species $(C$. concinnata, E. japonica, P. pavida, $S$. excisa and $Z$. libatrix) were identified at the species level. All of them are generalist parasitoids, attacking various species of Lepidoptera: (1) C. concinnata has an 
Table 5. Number of tachinid parasitoids emerging from each of 90 lepidopteran hosts parasitized by only a single tachinid species (Compsilura concinnata, Exorista japonica, Pales pavida, Senometopia excisa or Zenillia libatrix).

For details of hosts, see Table 1.

\begin{tabular}{|c|c|c|c|c|c|c|c|c|c|c|}
\hline \multirow{4}{*}{ Host } & \multicolumn{10}{|c|}{ Number of hosts parasitized by a single tachinid species } \\
\hline & \multicolumn{9}{|c|}{ Parasitizing tachinid species and number of tachinids emerging from a single host } & \multirow{3}{*}{ Total } \\
\hline & \multirow{2}{*}{$\frac{\text { C. concinnata }}{1}$} & \multicolumn{3}{|c|}{ E. japonica } & \multicolumn{2}{|c|}{ P. pavida } & \multicolumn{2}{|c|}{ S. excisa } & \multirow{2}{*}{$\frac{\text { Z. libatrix }}{1}$} & \\
\hline & & 1 & 2 & 3 & 1 & 2 & 1 & 2 & & \\
\hline Hyphantria cunea & 11 & 8 & 3 & - & 2 & - & - & - & - & 24 \\
\hline Phalera flavescens & - & - & - & - & - & - & 4 & 1 & - & 5 \\
\hline Pryeria sinica & 1 & - & - & - & - & - & - & - & - & 1 \\
\hline Pidorus glaucopis & - & 34 & 4 & 2 & 5 & 1 & - & - & 11 & 57 \\
\hline Chalcosia remota & 2 & - & - & - & - & - & - & - & - & 2 \\
\hline Dictyoploca japonica & - & - & - & - & - & 1 & - & - & - & 1 \\
\hline Total & 14 & 42 & 7 & 2 & 7 & 2 & 4 & 1 & 11 & 90 \\
\hline
\end{tabular}

Table 6. Number of tachinid species emerging from each of 157 tachinid-parasitized lepidopteran hosts. For details of hosts, see Table 1.

\begin{tabular}{|c|c|c|c|c|c|}
\hline \multicolumn{2}{|l|}{ Host } & \multicolumn{4}{|c|}{ Number of parasitized hosts } \\
\hline \multirow{2}{*}{ Species } & \multirow{2}{*}{$\begin{array}{c}\text { Collection } \\
\text { date }\end{array}$} & \multicolumn{3}{|c|}{ Number of tachinid species emerging from a single host } & \multirow{2}{*}{ Tota } \\
\hline & & 1 & 2 & $3-5$ & \\
\hline \multirow[t]{2}{*}{ Hyphantria cunea } & 26/8/97 & 16 & 1 & 0 & 17 \\
\hline & $1 / 9 / 97$ & 11 & 0 & 0 & 11 \\
\hline Phalera flavescens & $10 / 9 / 97$ & 17 & 0 & 0 & 17 \\
\hline Graphium sarpedon & $1 / 10 / 97$ & 0 & 0 & 1 & 1 \\
\hline \multirow{2}{*}{ Pryeria sinica } & $16 / 4 / 98$ & 2 & 0 & 0 & 2 \\
\hline & $30 / 4 / 98$ & 9 & 0 & 0 & 9 \\
\hline \multirow[t]{2}{*}{ Pidorus glaucopis } & $12 / 5 / 98$ & 24 & 0 & 0 & 24 \\
\hline & $21 / 5 / 98$ & 39 & 3 & 0 & 42 \\
\hline \multirow[t]{2}{*}{ Chalcosia remota } & $15 / 5 / 98$ & 16 & 0 & 0 & 16 \\
\hline & $18 / 5 / 98$ & 17 & 0 & 0 & 17 \\
\hline Dictyoploca japonica & $4 / 6 / 98$ & 1 & 0 & 0 & 1 \\
\hline Total & & 152 & 4 & 1 & 157 \\
\hline
\end{tabular}

extremely broad host range in Japan composed of 59 species from 20 families of Lepidoptera, including $C$. remota, $H$. cunea and $P$. sinica (Shima, 1999; pp. 14-16). Parasitization by C. concinnata was confirmed in C. remota, $H$. cunea and $P$. sinica in this study; (2) E. japonica also has a broad host range in Japan composed of 46 species from 17 families of Lepidoptera including $H$. cunea (Shima, 1999; pp. 6-9). Parasitization by E. japonica was confirmed in H. cunea in this study. In the present study, parasitization by E. japonica was also observed in $P$. glaucopis. This is the first record of $P$. glaucopis parasitized by E. japonica; (3) P. pavida has also a broad host range in Japan composed of 42 species from 15 families of Lepidoptera including H. cunea (Shima, 1999; pp. 5153). In the present study, parasitization by P. pavida was confirmed in $H$. cunea and was also observed in D. japonica and P. glaucopis. This is the first record of $D$. japonica and P. glaucopis being para- 
sitized by P. pavida; (4) the host range of $S$. excisa is composed of 9 species from 6 families of Lepidoptera including P. flavescens (Shima, 1999; p. 39). Parasitization by $S$. excisa was confirmed in $P$. flavescens in this study; and (5) the host range of $Z$. libatrix is composed of 8 species from 5 families of Lepidoptera (Shima, 1999; p. 56). In the present study, parasitization by $Z$. libatrix was observed in P. glaucopis. This is the first record of P. glaucopis parasitized by $Z$. libatrix.

As shown in Table 4, the number of tachinid larvae emerging from a single host individual was only 1 in 140 parasitized hosts. This suggests the possibility that a single tachinid emergence may have resulted from intra- or interspecific competition among tachinid larvae for the limited nutrients of the host. However, to obtain tangible evidence of competition is almost impossible at present because of technical difficulties, that is, it is hard to observe the inside of the intact parasitized hosts before the tachinid emergence. Emergence of more than 1 conspecific tachinid larva from a single host individual was observed in 13 hosts parasitized by E. japonica, P. pavida, S. excisa or Blepharipa $\mathrm{sp}$. (Tables 2a and 5). This may result from oviposition to a host previously parasitized by a tachinid female herself or by another conspecific female. Multiparasitism was also observed in 5 hosts and tachinid larvae of 2 or 3 to 5 species emerged from a single host individual (Table 6). In multiparasitism, at least 3 different types of species combinations were identified: (1) E. japonica and $P$. pavida; (2) E. japonica and Tachinidae sp.; and (3) Blepharipa sp. and Tachinidae spp. These results suggest that E. japonica, P. pavida, S. excisa and Blepharipa sp. larvae potentially have a high "tolerance" for the presence of other conspecific and/or heterospecific tachinid larvae. Iwao and Ohsaki (1996) also pointed out a high tolerance in C. concinnata larvae for the presence of other conspecific tachinid larvae. Of course, this does not mean that these tachinid larvae never compete for limited food resources.

A high tolerance in these tachinid species appears to be associated with an inability of a female fly to recognize previous parasitization in the host or their wide host range. For female hymenopteran parasitoids, the ability to discriminate between parasitized and unparasitized hosts at the time of oviposition has been reported by several authors (e.g. Hubbard et al., 1987; Völkl and Mackauer, 1990; McBrien and Mackauer, 1991; van Dijken et al., 1991; Visser, 1993). Although it is not known what mechanism the host discrimination is based on in the hymenopteran parasitoids, it seems very likely that chemoreception is involved. Weideli (1967) observed that the composition of the haemolymph of Drosophila melanogaster larvae changed qualitatively as well as quantitatively after parasitization by the parasitic wasp, Pseudeucoila bochei. Fisher and Ganesalingam (1970) also observed changes in the composition of haemolymph of the host Anagasta (Ephestia) kuehniella after attack by the parasitic wasp, Devorgilla (Nemeritis) canescens. In a scanning electron microscopic study, van Lenteren (1972) observed many receptor organs, probably contact-chemoreceptors, on the ovipositor of $P$. bochei, especially on the part actually inserted into the host during oviposition. He suggested that the host discrimination ability in $P$. bochei females may be based on the presence of the contact-chemoreceptors on the ovipositor. On the other hand, the host discrimination ability in female dipteran parasitoids is not well known. Tachinid females have no ovipositor and only glue their eggs on the host exoskeleton (e.g. E. japonica and S. excisa) or on a host plant of the host (e.g. P. pavida and Blepharipa sp.). They, therefore, may not be able to know whether the host was previously parasitized.

When parasitizing a wide range of host species, tachinid larvae will encounter many competitors. In such a situation, a high tolerance for the presence of other tachinid larvae would enable a tachinid larva to coexist tolerantly in a host with other tachinid larvae without direct and fatal intraand interspecific competition.

A decrease in puparial weight of a tachinid with an increasing number of tachinid puparia per host was found in Eucelatoria sp. by Ziser et al. (1977) and in L. archippivora by Stapel et al. (1997). Iwao and Ohsaki (1996) pointed out a tremendous plasticity in body size in the tachinid, $C$. concinnata: the smallest puparium weighed only $13 \%$ of the average of normal ones, yet it seemd to be perfectly capable of reproducing (K. Iwao, personal observation cited by Iwao and Ohsaki, 1996). They also pointed out that such a size plasticity is certainly useful in tolerating competition for the limited nutrients of a host. The presence of size plasticity is 
expected also in E. japonica, P. pavida, S. excisa and Blepharipa sp.

In conclusion, the present results suggest that $E$. japonica, P. pavida, S. excisa and Blepharipa sp. larvae potentially have a high tolerance for the presence of other tachinid larvae. Probably, this enables these tachinid larvae to coexist tolerantly with conspecific and/or heterospecific tachinid larvae in a host and, therefore, benefits their survival when there are not sufficient hosts available.

\section{ACKNOWLEDGEMENTS}

This publication is dedicated to the memory of the late Dr. Narao Fukuhara. We thank Drs. Tadakazu Nakashima, Kiyoshi Nakamuta, Masahiko Tokoro and Takenari Inoue of the Forestry and Forest Products Research Institute (FFPRI), Ibaraki, for encouragement. We are also grateful to Dr. Takashi Sato, Mr. Masahiko Suenaga and Mrs. Kayoko Asano for their skillful technical assistance. This study was financially supported by Japan Science and Technology Corporation.

\section{REFERENCES}

Allen, G. R. (1995) The biology of the phonotactic parasitoid, Homotrixa sp. (Diptera: Tachinidae), and its impact on the survival of male Sciarasaga quadrata (Orthoptera: Tettigoniidae) in the field. Ecol. Entomol. 20: $103-110$.

Cade, W. (1975) Acoustically orienting parasitoids: fly phonotaxis to cricket song. Science 190: 1312-1313.

Clausen, P. C. and J. L. King (1927) The parasites of Popilia japonica in Japan and Chosen (Korea), and their introduction into the United States. U. S. Dept. Agr. Dept. Bull. 1429: 1-55.

English-Loeb, G. M., R. Karban and A. K. Brody (1990) Arctiid larvae survive attack by a tachinid parasitoid and produce viable offspring. Ecol. Entomol. 15: 361-362.

Fisher, R. C. and V. K. Ganesalingam (1970) Changes in the composition of host haemolymph after attack by an insect parasitoid. Nature 227: 191-192.

Hubbard, S. F., G. Marris, A. Reynolds and G. W. Rowe (1987) Adaptive patterns in the avoidance of superparasitism by solitary parasitic wasps. J. Anim. Ecol. 56: 387-401.

Iwao, K. and N. Ohsaki (1993) Larval competitions and host choice by adults of parasitoid flies. The Nature and Insects 28: 27-32 (in Japanese).

Iwao, K. and N. Ohsaki (1996) Inter- and intraspecific interactions among larvae of specialist and generalist parasitoids. Res. Popul. Ecol. 38: 265-273.
Lehmann, G. U. C. and K-G. Heller (1998) Bushcricket song structure and predation by the acoustically orienting parasitoid fly Therobia leonidei (Diptera: Tachinidae: Ormiini). Behav. Ecol. Sociobiol. 43: 239-245.

McBrien, H. and M. Mackauer (1991) Decision to superparasitize based on larval survival: competition between aphid parasitoids: Aphidius ervi and Aphidius smithi. Entomol. Exp. Appl. 59: 145-150.

Oku, T. and T. Kobayashi (1974) Some dynamic aspects of field populations of the cabbage armyworm, Mamestra brassicae Linné, in Tohoku District. VI. Mortality factors of the later larval and pupal stages. Bull. Tohoku Natl. Agric. Exp. Stn. 47: 165-179 (in Japanese with English summary).

Robert, D., J. Amoroso and R. R. Hoy (1992) The evolutionary convergence of hearing in a parasitoid fly and its cricket host. Science 258: 1135-1137.

Shima, H. (1999) Host-parasite catalog of Japanese Tachinidae (Diptera). Makunagi/Acta Dipterologica Supplement 1: 1-108.

Stapel, J. O., J. R. Ruberson, H. R. Gross, Jr. and W. J. Lewis (1997) Progeny allocation by the parasitoid Lespesia archippivora (Diptera: Tachinidae) in larvae of Spodoptera exigua (Lepidoptera: Noctuidae). Environ. Entomol. 26: 265-271.

van Dijken, M. J., P. Neuenschwander, J. J. M. van Alphen and W. N. O. Hammond (1991) Sex ratios in field populations of Epidinocarsis lopezi, an exotic parasitoid of the cassava mealybug in Africa. Ecol. Entomol. 16: 233-240.

van Lenteren, J. C. (1972) Contact-chemoreceptors on the ovipositor of Pseudeucoila bochei Weld (Cynipidae). Neth. J. Zool. 22: 347-350.

Visser, M. E. (1993) Adaptive self- and conspecific superparasitism in the solitary parasitoid Leptopilina heterotoma (Hymenoptera: Eucoilidae). Behav. Ecol. 4: $22-28$.

Völkl, W. and M. Mackauer (1990) Age-specific pattern of host discrimination by the aphid parasitoid Ephedrus californicus Baker (Hymenoptera: Aphidiidae). Can. Entomol. 122: 349-361.

Walker, T. J. (1993) Phonotaxis in female Ormia ochracea (Diptera: Tachinidae), a parasitoid of field crickets. $J$. Insect Behav. 6: 389-410.

Weideli, H. (1967) Untersuchungen über die freien ninhydrin-positiven Substanzen und Proteine in der Haemolymphe der durch Schlupfwespen infizierten Larven von Drosophila melanogaster. Diplomarbeit. Zool. Insti. Univ. Zürich. 37 pp.

Ziser, S. W., J. A. Wojtowicz and W. C. Nettles, Jr. (1977) The effects of the number of maggots per host on length of development, puparial weight, and adult emergence of Eucelatoria sp. Ann. Entomol. Soc. Am. 70: 733-736. 